\title{
The effect of ketamine versus thiopental sodium on hemodynamic profile and seizure duration during electroconvulsive therapy in patients with major depressive disorder: A randomized cross-over clinical trial
}

\author{
Alireza Pournajafian ${ }^{1}$, Hamidreza Faiz ${ }^{1}$, Mohammad Ali Motazedi Ghajar ${ }^{1}$, Zahra Sadat Koleini ${ }^{1}$, Masood Mohseni*1미
}

Received: 29 Jan 2018

Published: 25 Feb 2020

\section{Abstract}

Background: Electroconvulsive therapy (ECT) is an effective treatment in major depressive disorder (MDD). Earlier studies suggest that ketamine has antidepressive effects and prolongs seizure duration in favor of therapeutic efficacy of ECT. A great concern with the use of ketamine is its possible adverse hemodynamic effects during ECT. This study was conducted to compare the hemodynamic effect and seizure duration between ketamine and sodium thiopental, a common anesthetic in ECT.

Methods: In a cross-over clinical trial, 26 patients of either sex with MDD who were candidates for ECT therapy in a university hospital were enrolled. A total of 13 patients received induction with ketamine in the first session and thiopental for the second. The sequence of treatments was vice versa in the other group. The followings were measured in all patients: blood pressure, heart rate, and oxygen saturation before induction, immediately after induction, at 1, 2, 4, and 10 minutes postinduction, and after recovery from anesthesia. Also, seizure duration, recovery time, and complications of treatments were measured. Chi square test and student $t$ test were used for categorical data and numerical data, respectively. $\mathrm{P}$ values $<0.05$ were considered statistically significant. Analyses were performed with SPSS software version 21.0.

Results: Heart rate, systolic and diastolic blood pressure, oxygen saturation, and recovery time were comparable between groups. Mean duration of convulsion in patients who received ketamine was significantly more than those who received STP ( $36 \pm 11$ vs $28 \pm 9 \mathrm{~s}$, $\mathrm{p}=0.001)$. Myalgia was less common in patients who received ketamine rather than sodium thiopental $(11.5 \mathrm{vs} 46.2 \%, p=0.014)$.

Conclusion: Ketamine prolongs seizure duration with no deleterious effects on hemodynamic parameters. Considering the antidepressant effects of ketamine, it may be a better choice, compared to thiopental sodium, for MDD patients.

Keywords: Major depressive disorder, Electroconvulsive therapy, Ketamine, Thiopental Sodium, Anesthesia, Hemodynamic

\section{Conflicts of Interest: None declared}

Funding: Departmental sources

*This work has been published under CC BY-NC-SA 1.0 license.

Copyright $\bigcirc$ Iran University of Medical Sciences

Cite this article as: Pournajafian A, Faiz H, Motazedi Ghajar MA, Koleini ZS, Mohseni M. The effect of ketamine versus thiopental sodium on hemodynamic profile and seizure duration during electroconvulsive therapy in patients with major depressive disorder: A randomized cross-over clinical trial. Med J Islam Repub Iran. 2020 (25 Feb);34:11. https://doi.org/10.47176/mjiri.34.11

\section{Introduction}

Electroconvulsive therapy (ECT) is a therapeutic approach proved for major depression (1). To convey ECT,

\section{Corresponding author: Dr Masood Mohseni, mohseni.ma@iums.ac.ir}

1. Department of Anesthesiology, Iran University of Medical Sciences, Tehran, Iran general anesthesia is administered for adequate analgesia and relaxation. To date, different drugs such as thiopental,

\section{$\uparrow$ What is "already known" in this topic:}

Ketamine has antidepressive effects and may prolong seizure duration in favor of therapeutic efficacy of electroconvulsive therapy (ECT). The fear of adverse effects during ECT and its possible impact on the recovery of patients have prohibited its routine use.

\section{$\rightarrow$ What this article adds:}

Ketamine prolongs seizure duration and reduces the incidence of post-ECT myalgia. It has no deleterious effects on hemodynamic parameters or duration of recovery. Thus, it may be a better choice compared to thiopental sodium in patients with major depressive disorder (MDD). 
methohexital, propofol, and etomidate have been administered. The dru gs have varying effects on duration and quality of seizure and hemodynamic changes (2-4). Although ECT may be generally safe, risks and possible complications like cognitive impairment and cardiovascular complications have been noted (5-7). As a result, different anesthetic agents have been used during the procedure to minimize adverse effects, keeping the hemodynamic profile stable, and favorably improving the quality of convulsion (8).

Thiopental sodium is an anesthetic widely used in general anesthesia. Like other barbiturates, it has anticonvulsive properties and reduces seizure duration. Ketamine is a noncompetitive high affinity $\mathrm{N}$ methyl D aspartate (NMDA) receptor antagonist and has antidepressant effects through glutamate pathways $(1,3)$. It has been suggested that those patients who received ketamine in ECT required less therapeutic sessions and had higher scores in the Hamilton rating scale (9). To our knowledge, the hemodynamic effects of ketamine in ECT have not been evaluated. This study was conducted to compare the effects of ketamine on seizure duration and hemodynamic profile with thiopental as the most commonly used anesthetic in ECT.

\section{Methods}

Patients with ASA physical status II-III were recruited in a university hospital setting (Rasoul Akram Medical Center), with no gender and age limitations, from Aug 2013 to April 2014. All participants had the diagnosis of major depression according to the Beck Depression Inventory Criteria and were candidates for electroconvulsive therapy. Patients who encountered significant side effects in the first session of therapy or missed the second session were excluded from the study. Patients with known true allergy to ketamine, thiopental sodium, or succinylcholine and those with documented prolonged convulsion (more than $1 \mathrm{mi}-$ nute) in the earlier treatment sessions were not included. Written informed consent was obtained from the patients' companions. With the approval of the medical ethics committee of the university, the clinical trial was registered in Iranian Registry of Clinical Trials (IRCT), with the code of 201306255026 N3.

\section{Study design}

In this cross-over clinical trial, 26 participants were randomly allocated by sealed envelopes to receive ketamine for the first and thiopental sodium for the second sessions or vice versa. Each patient received both treatments. Those who encountered significant side effects in the first session of therapy or did not return for the next session were excluded from the study.

After admission to the ECT room, patients lied down and one small bore intravenous catheter (usually 22G) was inserted on their hand or forearm. Patients were hydrated with normal saline $5 \mathrm{~mL} . \mathrm{kg}^{-1}$ and preoxygenated before induction of anesthesia. Participants were randomly allocated to receive Ketamine $0.3 \mathrm{mg} / \mathrm{kg}$ or thiopental sodium $2 \mathrm{mg} / \mathrm{kg}$ for induction of anesthesia. All patients received succinylcholine $0.5 \mathrm{mg} / \mathrm{kg}$ as muscle relaxant. After disappearance of muscular fasciculation or 40 seconds after anesthesia induction, ECT was performed by a psychiatrist. The machine for shock delivery was Thymatron ${ }^{\circledR}$ IV device (Somatics, LLC. Lake Bluff, IL, USA). The energy was adjusted on 35 voltage and subsequently increased by 10 voltages if the patient did not respond or showed insufficient seizure duration. Oxygen mask was placed on the face of the participants immediately after shock delivery and ventilated after termination of convulsion. The patients were monitored and cared for until meeting the discharge criteria. Then, IV catheter was removed and patients were transferred to the ward.

\section{Measurements}

The primary outcomes were the duration of convulsion and occurrence of clinically significant arrhythmias. The secondary outcomes were the duration of recovery, hemodynamic profile, and postconvulsion complications, including sialorrhea, myalgia, nausea, and agitation. Hemodynamic parameters were recorded before and during convulsion in 1, 2, 4, and 10 minutes after shock delivery. Blood pressure, heart rate, and oxygen saturation were measured with a standard noninvasive cardiovascular monitoring system (S1800, Saadat Company, Iran). To measure the duration of convulsion, a cuff was applied to the lower limb of the patients and the duration of jerking movements were recorded. Recovery was considered when patients followed the instructions and had stable hemodynamics. Complications, including bradycardia requiring atropine administration, significant tachyarrhythmia, postconvulsion nausea, and sialorrhea, were recorded. Sialorrhea was defined as a frequent need for suctioning. The patients were evaluated for the occurrence of myalgia 6 hours after ECT.

\section{Statistical analysis}

Sample size calculation was based on the estimation of the mean and variance of the treatment difference regarding the variable of 'duration of convulsion'. The approach of large sample size approximation ( $>12$ cases in either arm) was selected for feasibility (10). Demographic data and outcome measurements were analyzed using chi square test for categorical data and $t$ student test for numerical data. $\mathrm{P}$ values less than 0.05 were considered as statistically significant. All data were analyzed with SPSS version 21.0 (Chicago, IL, USA).

\section{Results}

In this study, 32 participants were enrolled and 26 patients remained in analysis, including 12 women and 14 men (Fig. 1. CONSORT diagram). The mean duration of convulsion in patients who received ketamine was significantly more than those who received STP $(36 \pm 11$ vs $28 \pm 9$ $\mathrm{s}, \mathrm{p}=0.001)$.There were no statistical significant differences in systolic and diastolic blood pressure and heart rate between the 2 groups (Table 1). Similarly, recovery time was comparable between the 2 groups (ketamine, $15 \pm 5$ vs STP, $16 \pm 4 \mathrm{~min} ; \mathrm{p}=0.592$ ).

Myalgia was significantly less frequent in patients who received ketamine than those who induced with STP. Brad- 


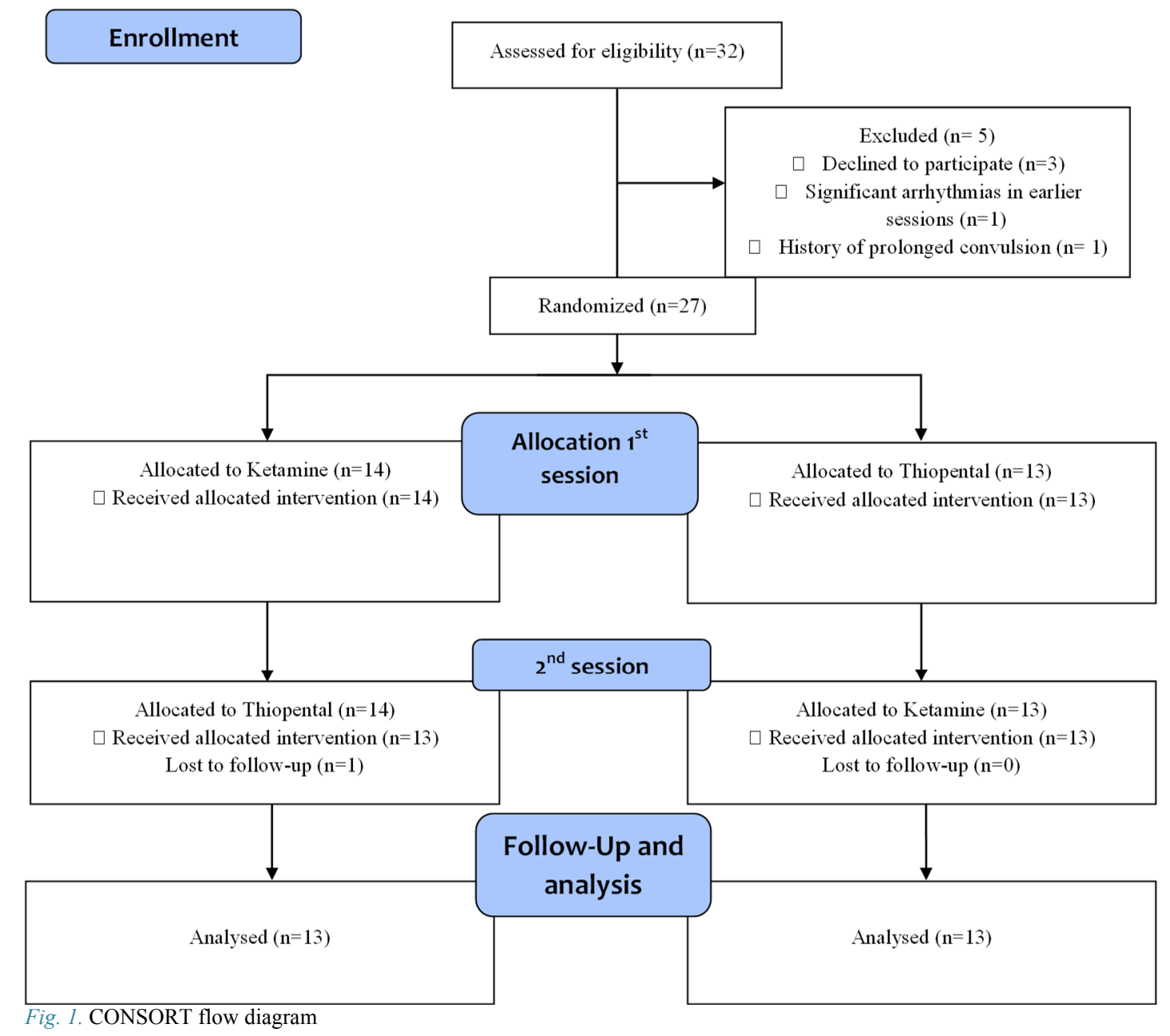

ycardia requiring atropine administration was equally recorded in both groups (3.8\%). Agitation and sialorrhea were more frequent in patients receiving ketamine than their counterparts, but the difference was not statistically significant (Table 2).

\section{Discussion}

Ketamine has been reported to improve cognitive and antidepressant effects and to protect against memory loss after ECT (3). Previous studies compared the effects of ketamine

Table 1. Hemodynamic measurements in two groups

\begin{tabular}{|c|c|c|c|c|c|c|c|c|c|c|}
\hline \multirow[b]{2}{*}{ Time Intervals } & \multirow[b]{2}{*}{ Medication } & \multicolumn{3}{|c|}{ Systolic blood pressure } & \multicolumn{3}{|c|}{ Diastolic blood pressure } & \multicolumn{3}{|c|}{ Heart rate } \\
\hline & & $\begin{array}{c}\text { Group1 } \\
(n=13)\end{array}$ & $\begin{array}{c}\text { Group2 } \\
(\mathrm{n}=13)\end{array}$ & $\begin{array}{c}\text { Total } \\
(\mathrm{n}=26)\end{array}$ & $\begin{array}{c}\text { Group1 } \\
(n=13)\end{array}$ & $\begin{array}{l}\text { Group2 } \\
(\mathrm{n}=13)\end{array}$ & $\begin{array}{c}\text { Total } \\
(\mathrm{n}=26)\end{array}$ & $\begin{array}{c}\text { Group1 } \\
(\mathrm{n}=13)\end{array}$ & $\begin{array}{c}\text { Group2 } \\
(\mathrm{n}=13)\end{array}$ & $\begin{array}{c}\text { Total } \\
(\mathrm{n}=26)\end{array}$ \\
\hline After & Ketamine & $142(23)$ & 139 (17) & $140(20)$ & $86(11)$ & $85(7)$ & $85(9)$ & $85(10)$ & $85(15)$ & $83(14)$ \\
\hline induction & Thiopental & $134(26)$ & 137 (19) & $135(22)$ & $82(14)$ & $88(14)$ & $85(14)$ & $76(11)$ & $88(12)$ & $82(13)$ \\
\hline \multirow[t]{2}{*}{ Min 1} & Ketamine & $166(26)$ & $170(33)$ & $186(29)$ & $101(13)$ & $93(20)$ & $97(17)$ & $94(18)$ & $84(17)$ & $89(18)$ \\
\hline & Thiopental & $165(36)$ & $148(10)$ & $156(27)$ & $103(22)$ & $95(7)$ & 99 (14) & $83(12)$ & $94(18)$ & $88(16)$ \\
\hline \multirow[t]{2}{*}{ Min 3} & Ketamine & $148(16)$ & $161(23)$ & $154(20)$ & $90(11)$ & $90(18)$ & $90(14)$ & $92(20)$ & $83(16)$ & $87(19)$ \\
\hline & Thiopental & $163(40)$ & $143(18)$ & $153(32)$ & $99(23)$ & $96(15)$ & $98(19)$ & $83(21)$ & $88(13)$ & $85(17)$ \\
\hline \multirow[t]{2}{*}{ Min 5} & Ketamine & $138(16)$ & $150(17)$ & $144(17)$ & $85(11)$ & $85(14)$ & $85(12)$ & $85(13)$ & $83(17)$ & $84(15)$ \\
\hline & Thiopental & $148(27)$ & $142(18)$ & $145(22)$ & $93(18)$ & $92(17)$ & $92(17)$ & $82(16)$ & $92(25)$ & $87(21)$ \\
\hline \multirow[t]{2}{*}{ Min 10} & Ketamine & $133(15)$ & $141(17)$ & $137(16)$ & $86(8)$ & $83(12)$ & $84(10)$ & $83(10)$ & $81(9)$ & $82(9)$ \\
\hline & Thiopental & $140(23)$ & $136(13)$ & $138(18)$ & $90(18)$ & $85(9)$ & $88(14)$ & $58(14)$ & $85(13)$ & $85(13)$ \\
\hline \multirow{2}{*}{$\begin{array}{l}\text { After } \\
\text { convulsion }\end{array}$} & Ketamine & $128(10)$ & $134(16)$ & $131(14)$ & $84(6)$ & $80(8)$ & $82(7)$ & $82(6)$ & $81(8)$ & $81(7)$ \\
\hline & Thiopental & $130(15)$ & $130(12)$ & $130(14)$ & $86(11)$ & $80(10)$ & $83(11)$ & $83(10)$ & $82(9)$ & $82(10)$ \\
\hline & & & $\begin{array}{c}\text { Ketamine } \\
(\mathrm{n}=26)\end{array}$ & $\begin{array}{r}\text { Thiope } \\
(\mathrm{n}=2\end{array}$ & & & & $\mathrm{P}$ value & & \\
\hline Severe bradycardia & & & $1(3.8)$ & $1(3$ & & & & 1.000 & & \\
\hline Agitation & & & $2(7.7)$ & $0(0$ & & & & 0.492 & & \\
\hline Nausea & & & $1(3.8)$ & $2(7$. & & & & 0.952 & & \\
\hline Sialorrhea & & & $3(11.5)$ & $1(3$ & & & & 0.614 & & \\
\hline Myalgia & & & $3(11.5)$ & $12(4$ & & & & 0.012 & & \\
\hline
\end{tabular}


and thiopental on convulsion profile in ECT patients (3, 11). Patients receiving ketamine had longer duration of convulsion and better cognitive function and recovery from depression (12-14). Ketamine blocks NMD receptors; thus, stimulating glutamate releases and has antidepressant effects. Similarly, the results of this study showed that the administration of ketamine is associated with longer duration of convulsion with good enough recovery profile compared to thiopental sodium.

Increased blood pressure and heart rate are potential hemodynamic adverse effects of ketamine administration. However, ketamine did not cause adverse hemodynamic effects in the patients. An earlier study suggested that ketamine and etomidate provide better quality and duration of convulsion, whereas maximum systolic blood pressure and heart rate would be higher with the use of ketamine and lower with propofol administration (5). Similarly, in this study, increased heart rate and mean arterial blood pressure was observed with ketamine administration, which may be due to increased catecholamine secretion and decreased synaptic uptake $(2,8)$. However, the maximum heart rate was comparable between the 2 groups and the use of ketamine did not influence the occurrence of tachyarrhythmia necessitating drug intervention. Nevertheless, it seems reasonable to be cautious in using ketamine in patients with cardiovascular morbidities (5).

Recovery time was similar in the 2 groups. The duration of action of ketamine with a dose of $2 \mathrm{mg} / \mathrm{kg}$ is 10 to 15 minutes. However, the low required dose of ketamine in the ECT offers the fast recovery from anesthesia and convulsion. Ketamine $0.3 \mathrm{mg} / \mathrm{kg}$ was administered, which is satisfactorily sufficient for the induction of anesthesia in ECT patients. To our knowledge, it should be administered slowly and let it affect the level of consciousness, patiently before the induction of convulsion by electrical discharge. the lower incidence of myalgia with the use of ketamine was recorded, which could be reasonably explained by its analgesic effects (15). In this study, the only disadvantage of ketamine versus STP was more frequent sialorrhea.

According to the cross-over design, every patient was compared with him/herself. Elimination of confounding factors due to differences in baseline characteristics was the strength of this study. A concern in cross-over clinical trials is the possibility of carry-over effect between treatments, which confounds the estimates of the treatment effects. Since the half-life of a single dose of administered anesthetics is in the boundary of minutes, 2 days of wash-out period makes the carry-over effect unlikely. Nevertheless, this study had some limitations. Long term effects of ECT on depression and cognitive impairment was not record. Another limitation was variable voltages used in the 2 sessions of ECT, which was applied due to psychiatric remedies.

\section{Conclusion}

In conclusion, ketamine seems to be a reasonable choice for anesthesia for ECT because of its convulsion profile, fast recovery from anesthesia, stable hemodynamic profile, and analgesic effect. Moreover, its antidepressant effects will make it a more favorable choice in patients with depression disorder.
Conflict of Interests

The authors declare that they have no competing interests.

\section{References}

1. Ibrahim L, Diazgranados N, Luckenbaugh DA, Machado-Vieira R, Baumann J, Mallinger AG, et al. Rapid decrease in depressive symptoms with an N-methyl-d-aspartate antagonist in ECT-resistant major depression.Prog Neuropsychopharmacol Biol Psychiatry. 2011;35(4):1155-9.

2. Kranaster L, Kammerer-Ciernioch J, Hoyer C, Sartorius A. Clinically favourable effects of ketamine as an anaesthetic for electroconvulsive therapy: a retrospective study. Eur Arch Psychiatry Clin Neurosci. 2011;261(8):575-82.

3. Yoosefi A, Sepehri AS, Kargar M, Akhondzadeh S, Sadeghi M, Rafei A, et al. Comparing effects of ketamine and thiopental administration during electroconvulsive therapy in patients with major depressive disorder: a randomized, double-blind study. J ECT. 2014;30(1):15-21.

4. Trevithick L, McAllister-Williams RH, Blamire A, Branton T, Clark $\mathrm{R}$, Downey D, et al. Study protocol for the randomised controlled trial: Ketamine augmentation of ECT to improve outcomes in depression (Ketamine-ECT study). BMC psychiatry. 2015;15:257.

5. Hoyer C, Kranaster L, Janke C, Sartorius A. Impact of the anesthetic agents ketamine, etomidate, thiopental, and propofol on seizure parameters and seizure quality in electroconvulsive therapy: a retrospective study. Eur Arch Psychiatry Clin Neurosci. 2014;264(3):255-61

6.Zahavi GS, Dannon P. Comparison of anesthetics in electroconvulsive therapy: an effective treatment with the use of propofol, etomidate, and thiopental. Neuropsychiatr Dis Treat. 2014;10:383-9

7. Grant IS, Nimmo WS, McNicol LR, Clements JA. Ketamine disposition in children and adults. Br J Anaesth. 1983;55(11):1107-11

8. Copeland J, Dillon P. The health and psycho-social consequences of ketamine use. Int J Drug Policy. 2005;16(2):122-31.

9. McDaniel WW, Sahota AK, Vyas BV, Laguerta N, Hategan L, Oswald J. Ketamine appears associated with better word recall than etomidate after a course of 6 electroconvulsive therapies. J ECT. 2006;22(2):1036.

10. Siyasinghe MM, Sooriyarachchi MR. Guidelines for calculating sample size in 2x2 crossover trials: a simulation study. J Natn Sci Foundation Sri Lanka. 2011;39(1):77-89.

11. Salehi B, Mohammadbeigi A, Kamali AR, Taheri-Nejad MR, Moshiri I. Impact comparison of ketamine and sodium thiopental on anesthesia during electroconvulsive therapy in major depression patients with drug-resistant; a double-blind randomized clinical trial. Ann Card Anaesth. 2015;18(4):486-90.

12. Fond G, Bennabi D, Haffen E, Brunel L, Micoulaud-Franchi JA, Loundou A, et al. A Bayesian framework systematic review and metaanalysis of anesthetic agents effectiveness/tolerability profile in electroconvulsive therapy for major depression. Sci Rep. 2016;6:19847.

13. Kucia K, Merk W. The use of ketamine in electroconvulsive therapy. Psychiatr Pol. 2015;49(6):1255-63.

14. Abdallah CG, Fasula M, Kelmendi B, Sanacora G, Ostroff R. Rapid antidepressant effect of ketamine in the electroconvulsive therapy setting. J ECT. 2012;28(3):157-61.

15. Freye E, Latasch L, Schmidhammer H, Portoghese P. [Interaction of S-(+)-ketamine with opiate receptors. Effects on EEG, evoked potentials and respiration in awake dogs]. Anaesthesist. 1994;43 Suppl 2:S52-8. 